\section{Synopsis from an Editor}

\section{Introduction}

International Robotics \& Automation Journal (IRATJ) is an international scholarly, peer review, open Access journal, initiated with an aim to promote the research and development in Robotics \& Automation technology and technology breakthrough.

\section{Peer review process}

Peer review plays a very important role in ensuring the integrity of the scholarly record for our system. The process depends on a large extent on trust, and requires that everyone involved behaves responsibly and ethically. Peer reviewers play a central and critical part in the peer-review process. We get at least two independent reviews of each full length article and at least one for short report letters. We use a double-blind reviewing process in which author's and reviewer's identities are concealed. Our reviewers are encouraged to provide substantive, constructive reviews that provide suggestions for improving the work and distinguish between mandatory and nonmandatory recommendations. The handling editor considers all the returned reviews before making an overall decision. If the reviews differ widely, the editor may invite an additional reviewer so as to get an extra opinion before making a decision.

\section{Ethical standards}

We at MedCrave take Ethics very seriously. We think Ethics should be followed to get better results not only in professional but also in our personal life. We accept manuscripts for publication only if it is made clear that investigations were carried out to a high ethical standard.

\section{Advantages of international robotics \& automation journal (IRATJ)}

International Robotics and Automation Journal (IRATJ) have already many theoretical, computational, experimental and practical aspects of autonomous systems, and/or modules of such systems. This journal is very broadly classified in not only in design, construction, operation, and use of robots, as well as computer systems for their control, sensory feedback and information processing systems. That being said we also go beyond industrial, domestic/household, medical, and service, military, entertainment, space, hobby and competition robot developments for instance manipulation robotic system, mobile robotics, data acquisition and control robotic system. Because of the complexity and broad nature of our journal, if for some reason we were not able to fit your article into our International Robotics \& Automation Journal we may be able to create a brand new Robotics journal specific to the technology if the article is breakthrough technology.

\section{How does International robotics \& automation journal beneficial for authors?}

There are many advantages for authors and researchers for instance we provide free Pdf for open source articles, liberal copyright policy, discounts for low income authors, researchers.

a. We encourage articles from anyone including government, non-profit organization, private institutions and individuals at international level.
Volume 2 Issue 6 - 2017

Manu Mitra
Department of Alumnus with Electrical Engineering, University
of Bridgeport, USA

Correspondence: Manu Mitra, Department of Alumnus with Electrical Engineering, University of Bridgeport, USA, Email mmitra@my.bridgeport.edu

Received: August 10,2017| Published: August 17, 2017

b. Proofs: We will email a PDF of the proofs to the corresponding author.

c. E-Prints and Complimentary Copies: MedCrave provides authors with access to a PDF of their final article including Digital Object Identifier (DOI)

d. At MedCrave we place an extremely strong emphasis on the highest production standards possible. We attach high importance to our quality service levels in copy-editing, typesetting, printing, and online publication.

We also seek to uphold excellent author relations throughout the publication process. We value your feedback to ensure that we continue to improve our author service levels. On publication all corresponding Authors may receive a brief survey questionnaire on your experience of publishing in the Journal.

\section{Questions for authors}

Did you register your profile in ORCID?

Distinguish yourself. ORCID provides a persistent digital identifier that distinguishes you from every other researcher and through integration in key research workflows such as manuscript and grant submission, supports automated linkages between you and your professional activities ensuring that your work is recognized.

\section{Feedback system}

Here at MedCrave we take feedback seriously especially at International Robotics and Automation Journal and we think that we can improve system based on not just on article submission but also through recommendations, opinions, reviews, suggestions and other ideas that helps to move forward with research and development.

\section{Acknowledgments \\ None.}

\section{Conflict of interest}

Author declares that there is none of the conflicts. 